\title{
Physical Mapping of 5S rRNA Genes in Cycas revoluta
}

\author{
M. Hizume \\ Biological Institute, Faculty of Education, Ehime University, Matsuyama 790, Japan
}

Accepted October 4, 1995

Among the cycads Cycas revoluta $(2 n=22)$ has been the most investigated species cytologically. The informations on the chromosomes of $C$. revoluta are deposited regarding to meiosis (Nakamura 1929), karyotype (Sax and Beal 1934, Segawa et al. 1971, Selvaraj 1980, Kokubugata and Kondo 1994, Kondo et al. 1995), C-banding (Tanaka and Hizume 1980), fluorescent banding using base specific fluorochromes, NOR (nucleolar organizing region) staining, Cd-staining and in situ hybridization (ISH) with 18S-5.8S-26S rRNA gene (Hizume et al. 1992). Genomic DNA content of C. revoluta nucleus was 10.3 or $12.7 \mathrm{pg}$ per haploid genome (Kurdi-Haider et al. 1983, Ohri and Khoshoo 1986). There is a few molecular analysis on nuclear genome of this species. Base sequence was reported only in 5S rRNA (Erdmann and Wolters 1986) and DNA sequence organization in the genome was investigated by Cot analysis by Kurdi-Haidar et al. (1983).

While 18S-5.8S-26S rDNA had been mapped physically on the metaphase chromosomes using the heterogenerous rDNA cloned from wheat genome (Hizume et al. 1992), no other sequence was mapped. As the 5S rDNA composed of highly conservative 5S rRNA sequence and the spacer variable in length and sequence among taxa is tandemly arrayed in the eukaryotic genome (Long and Dawid 1980), the spacer of 5S rDNA repeat unit was easily amplified in several plants by PCR uisng the universal primers possessing the base sequence correspond to a part of 5S rRNA consensus sequence (Cox et al. 1992). The 5S rDNA amplified by PCR has been successfully used as a probe for ISH in Vicia faba, Crepis capillaris (Hizume 1993), Allium cepa, A. fistulosum (Hizume 1994), A. sativum (Hizume et al. 1994), Hordeum vulgare (Fukui et al. 1994) and Oryza sativa (Kamisugi et al. 1994). I report here the physical mapping of $5 \mathrm{~S}$ rRNA genes on the somatic chromosomes in C. revoluta.

\section{Materials and methods}

Young leaves collected from a male plant of Cycas revoluta Thunb. in mid June were cut into small pieces about $1 \mathrm{~mm}$ across and treated with $0.05 \%$ colchicine or $2 \mathrm{mM} 8$-hydroxyquinoline at room temperature for $6 \mathrm{hr}$. The materials were fixed with acetic acid-ethanol $(1: 3)$, and then washed with $70 \%$ ethanol and distilled water each for $10 \mathrm{~min}$ and treated with 2\% Cellulase Onozuka RS (Yakult Honsya) and 0.5\% Pectolyase Y-23 (Seishin Pharmaceutical) in $0.05 \mathrm{M}$ citrate buffer $(\mathrm{pH} 4.5)$ at $37^{\circ} \mathrm{C}$ for $1 \mathrm{hr}$. After washing with distilled water for $15 \mathrm{~min}$, the materials were squashed in $45 \%$ acetic acid on glass-slides. The coverslips were removed from glass-slides by dry-ice technique and then the chromosome preparations were air-dried.

Total genomic DNA was extracted from young leaves by CTAB method. The 5S rDNA fragment was amplified by PCR (Saiki et al. 1988) using a template of the genomic DNA and the primer set of parts of highly conserved 5S RNA gene. Based on a comparison of sequences of 5 S rRNA of C. revoluta (Erdmann and Wolters 1986) and several angiospermous plants (Ellis et al. 1988, Wolters and Erdmann 1988). The sets of primers which directed inside or outside of 5S rRNA sequence were synthesized. The sequences of the primers were as follows: 
5SS1: 5'-AGGTGCGATATACCAGC-3' (nt 1-18 of the 5S rRNA sequence) and 5SS2: 5' GGGTGCAATATTAGGACTT-3' (nt 118-100) for 5S rRNA region, and 5SL1: 5'. CGGTGCATTAATGCTGGTAT-3' (nt 10-30), 5SL2: 5'-CCATCAGAACTCCGCAGTTA$3^{\prime}$ (nt 34-54) for repeat unit. Detail of PCR conditions have been described by Hizume (1993). Sizes of amplified fragments were analyzed by electrophoresis on $2 \%$ agarose gel with a size marker of the $100 \mathrm{bp}$ ladder (BRL). The amplified DNA was labeled with biotin-dATP by nick translation or PCR, and then used as a probe for ISH. The probe mixture of $10 \mu 1$ containing $25 \mathrm{ng}$ labeled DNA in $50 \%$ formamide and $2 \times \mathrm{SSC}$ was applied to the chromosome preparation. After sealing under a coverslip with rubber cement the chromosomal and probe DNAs in the preparation were simultaneously denatured on a hotplate set at $78^{\circ} \mathrm{C}$ for $10 \mathrm{~min}$. The other ISH protocol was performed following the procedure of Hizume et al. (1992) and Hizume (1993). After the ISH, the chromosome arms were counterstained with $2 \%$ Giemsa in $2 \times$ SSC for $2 \mathrm{~min}$.

Results and discussion

The DNA fragment amplified from the template of total $C$. revoluta genomic DNA by

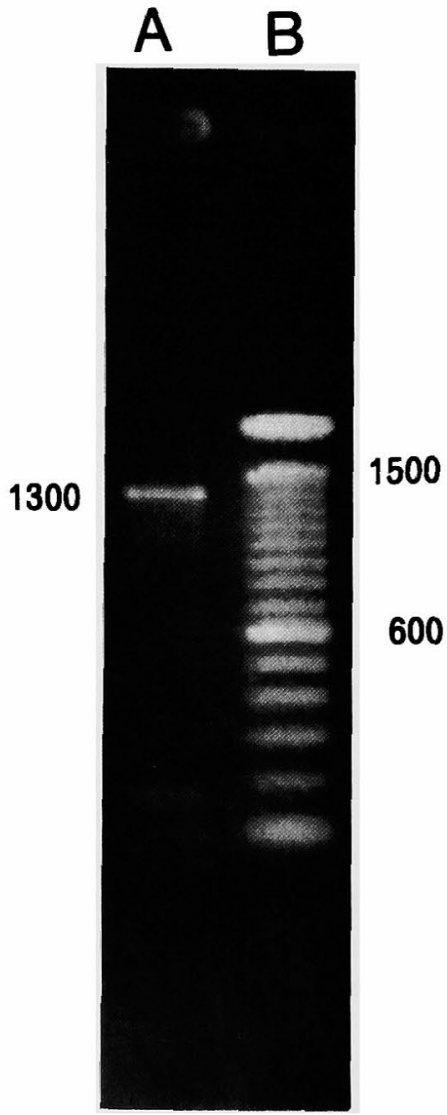

Fig. 1. Electrophoresis of 5S rDNA fragment amplified by PCR using the primer for 5S rDNA repeat unit from genomic DNA of Cycas revoluta on 2\% agarose gel. A: PCR amplified fragment with about $1300 \mathrm{bp}$, B: 100 bp ladder (BRL).
PCR using the primer sets for 5S rDNA repeat unit or 5S rRNA sequence region were about 1300 bp (Fig. 1) or $120 \mathrm{bp}$, respectively. The 1300 bp $5 \mathrm{~S}$ rDNA repeat unit of $C$. revoluta given was somewhat shorter than the previous data (1572 bp) analyzed by southern hybridization of Bam HI digested genomic DNA (Gottlob-Mchugh et al. 1990). The biotin-labeled 5S rDNAs were hybridized in situ to the Vicia faba chromosomes in which the 5S rDNA loci are well known. Two ISH signals appeared at the satellite of the longest metacentric chromosome (data not shown) same as previous reports (Knälmann and Burger 1977, Schubert et al. 1978, Hizume 1993). The fact indicated that 5S rDNAs were successfully amplified by PCR in this experiment.

Interphase nuclei and mitotic chromosomes had clear, heavy signals indicating hybridization with the probe of 5S rDNA repeat unit or 5S rRNA sequence region (Fig. 2). All interphase nuclei had two signals each (Fig. 2A). The 5S rDNA sites of homologous chromosomes separated always and did not fuse in any phases of mitosis (Figs. 2B, D). The karyotype of $C$. revoluta was composed of two pairs of large submetacentric chromosome, five pairs of medium-sized telocentric chromosomes and four pairs of small metacentric chromosomes, and confirmed that reported previously (Sax and 


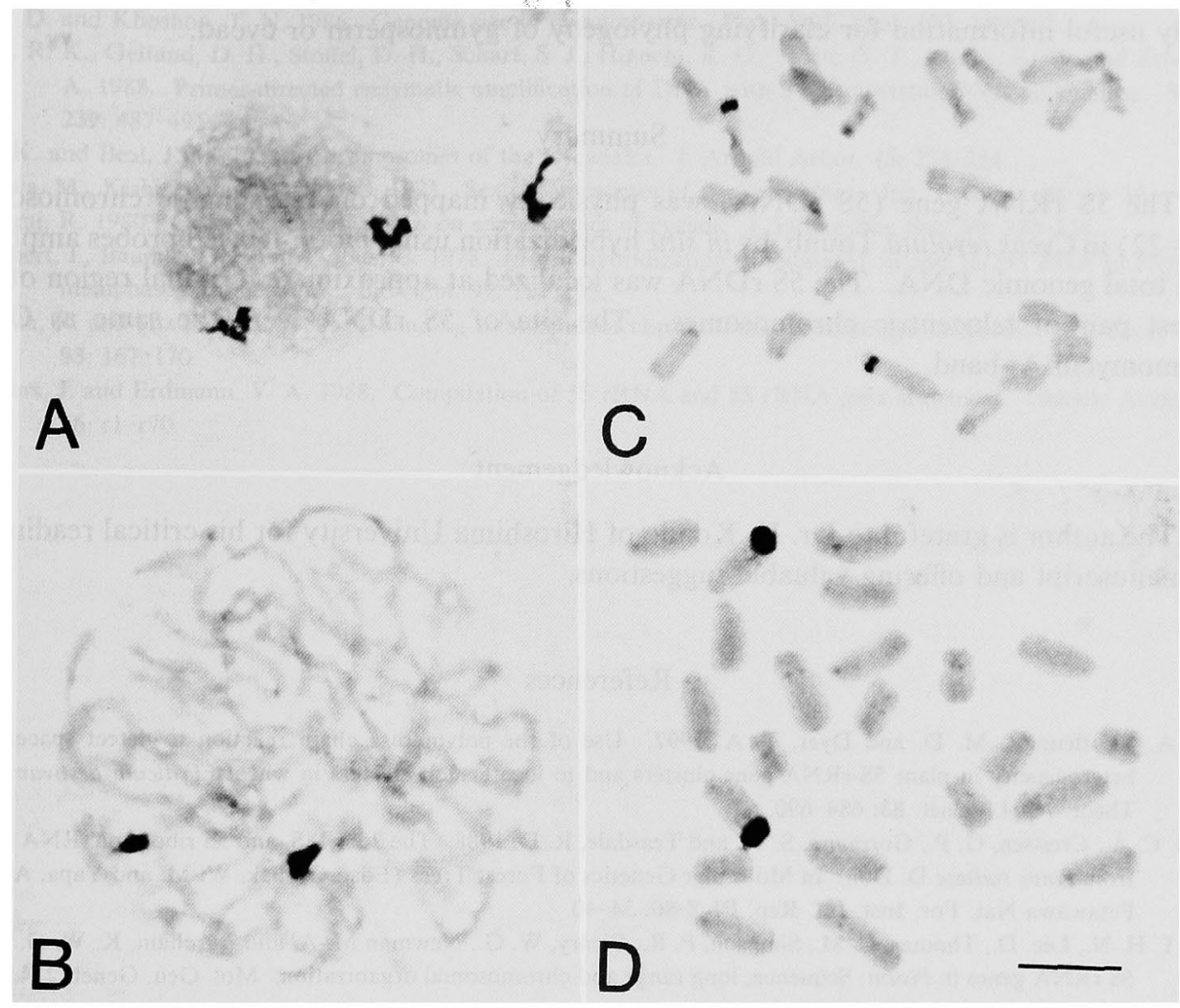

Fig. 2. Interphase nucleus (A), somatic prophase chromosomes (B) and metaphase chromosomes $(2 n=22)(C, D)$ of Cycas revoluta hybridized in situ with biotin-labeled 5S rDNA repeat unit $(A, B, D)$ and $5 S$ RNA coding region (C). $B a r=10 \mu \mathrm{m}$.

Beal 1934, Segawa et al. 1971, Selvaraj 1980, Kokubugata and Kondo 1994, Kondo et al. 1995). The 5S rDNA locus was localized at approximate terminal region of the longest pair of telocentric chromosomes (the 3rd pair) (Fig. 2D). After counterstaining with Giemsa a pair of dots appeared at the centromere of each metaphase chromosomes was stained with Giemsa like Cd-bands (Hizume et al. 1993), and was not a signal of ISH. When the probe of $120 \mathrm{bp} 5 \mathrm{~S}$ rRNA gene sequence was used, the signals were somewhat weaker than those obtained using the whole repeat unit and the location of the signals was the same as that of the repeat unit (Figs. 2C, D). The fact indicates that any homologous sequences to the spacer of the 5S rDNA were not distributed on the chromosome of $C$. revoluta excepting for $5 \mathrm{~S}$ rDNA locus.

The site of 5S rDNA can be compared with C-bands reported by Tanaka and Hizume (1980) and chromomycin $\mathrm{A}_{3}$ (CMA)- and DAPI-bands, Ag-NORs and sites of 18S-5.8S-26S rDNA reported by Hizume et al. (1992). The 5S rDNA locus was exactly the same location as the C-band or the CMA-band at approximate terminal region of the long arm of the longest pair of telocentric chromosomes (the 3rd pair). As the karyotype has been very similar to each other in Cycas species (Kondo et al. 1995), the 5S rDNA locus may be useful marker for comparative karyotype analysis in the genus.

In other gymnosperms the size of 5S rDNA repeat unit was 525 and 850 bp in Pinus radiata (Cullis et al. 1988, Moran et al. 1992), 378 bp in Junipers virginiana (Gottlob-Mchugh et al. 1990). It is not clear that the long 5S rDNA repeat unit observed in $C$. revoluta is specific to 
cycads in general, the genus Cycas or the species. The analysis of sequence of $5 \mathrm{~S}$ rDNA may supply useful information for clarifying phylogeny of gymnosperm or cycad.

\section{Summary}

The 5S rRNA gene (5S rDNA) was physically mapped on the somatic chromosomes $(2 n=22)$ in Cycas revoluta Thunb. by in situ hybridization using biotin-labeled probes amplified from total genomic DNA. The 5S rDNA was localized at approximate terminal region of the longest pair of telocentric chromosomes. The site of $5 \mathrm{~S}$ rDNA were the same as $\mathrm{C}$ - or chromomycin $\mathrm{A}_{3}$-band.

\section{Acknowledgement}

The author is grateful to Dr. K. Kondo of Hiroshima University for his critical reading of the manuscript and offering valuable suggestions.

\section{References}

Cox, A. V., Bennett, M. D. and Dyer, T. A. 1992. Use of the polymerase chain reaction to detect spacer size heterogeneity in plant 5S-rRNA gene clusters and to locate such clusters in wheat (Triticum aestivum L.). Theor. Appl. Genet. 83: 684-690.

Cullis, C. A., Creissen, G. P., Gormann, S. W. and Teasdale, R. D. 1988. The 25S, 18S, and 5S ribosomal RNA genes from Pinus radiate D. Don. In Molecular Genetics of Forest Trees (Eds.: Cheliak, W. M. and Yapa, A. C.). Petawawa Nat. For. Inst. Inf. Rep. PI-X-80: 34-40.

Ellis, T. H. N., Lee, D., Thomas, C. M., Simpson, P. R., Cleary, W. G., Newman M.-A. and Burcham, K. W. G. 1988. 5S rRNA genes in Pisum: Sequence, long range and chromosomal organization. Mol. Gen. Genet. 214: 333342.

Erdmann, V. A. and Wolters, J. 1986. Collection of published 5S, 5.8S and 4.5S RNA sequences. Nucleic Acids Res. 14: $\mathrm{r} 1-\mathrm{r} 59$.

Fukui, K., Kamisugi, Y. and Sakai, F. 1994. Physical mapping of 5S rDNA loci by direct-cloned biotinylated probes in barley chromosomes. Genome 37: 105-111.

Gottlob-Mchugh, S. G., Levesque, M., MacKenzie, K., Olson, M., Yarosh, O. and Johnson D. A. 1990. Organization of the 5S rRNA genes in the soybean Glycine $\max$ (L.) Merrill and conservation of the 5S rDNA repeat structure in higher plants. Genome 33: 486 494.

Hizume, M. 1993. Chromosomal localization of 5S rRNA genes in Vicia faba and Crepis capillaris. Cytologia 58: 417421.

- 1994. Allodiploid nature of Allium wakegi Araki revealed by genomic in situ hybridization and localization of $5 S$ and 18S rDNAs. Jpn. J. Genet. 69: 407-415.

-, Ishida, F. and Kondo, K. 1992. Differential staining and in situ hybridization of nucleolar organizers and centromeres in Cycos revoluta chromosomes. Jpn. J. Genet. 67: 381-387.

Kamisugi, Y., Nakayama, S., Nakajima, R., Ohtsubo, H., Ohtsubo, E. and Fukui, K. 1994. Physical mapping of the 5S ribosomal RNA genes on rice chromosome 11. Mol. Gen. Genet. 245: 133-138.

Knälmann, M. and Burger, E. C. 1977. Cytologische Lokalisation von 5S und 18/25S RNA Genorten in MitoseChromosomen von Vicia faba. Chromosoma 61: 177-192.

Kokubugata, G. and Kondo, K. 1994. Quantitative variability in karyotype of Cycas revoluta. Kromosomo 11-75-75: 2613-2618.

Kondo, K., Kokubutaga, G., Hizume, M., Tanaka, R. and Satake, T. 1995. A karyomorphological study of five species and one variety of Cycas. Cytologia 60: 141-147.

Kurdi-Haidar, B., Shalhoub, V. Dib-Hajj, S. and Deeb, S. 1983. DNA sequence organization in the genome of Cycas revoluta. Chromosoma 88: 319-327.

Long, E. O. and Dawid, I. B, 1980. Repeated genes in eukaryotes. Annu. Rev. Biochem. 49: 727-764.

Moran, G. F., Smith, D., Bell, J. C. and Appels, R. 1992. The 5S RNA genes in Pinus radiata and the spacer region as a probe for relationships between Pinus species. Plant Syst. Evol. 183: 209-221.

Nakamura, T. 1929. Chromosome arrangement. IX. The pollen mother cells in Cycas revoluta Thunb. Mem. Coll. Sci. 
Kyoto Imp. Univ., B 9: 353-369.

Ohri, D. and Khoshoo, T. N. 1986. Genome size in gymnosperms. Plant Syst. Evol. 153: 119-132.

Saiki, R. K., Gelfand, D. H., Stoffel, D. H., Scharf, S. J., Higuchi, R. G., Horn, G. T., Mullis, K. B., and Erlich, H. A. 1988. Primer-directed enzymatic amplification of DNA with a thermostable DNA polymerase. Science 239: $487-491$.

Sax, K. and Beal, J. M. 1934. Chromosomes of the Cycadales. J. Arnold Arbor. 15: 255-258.

Segawa, M., Kishi, S. and Tatsuno, S. 1971. Sex chromosomes of Cycas revoluta. Jpn. J. Genet. 46: 33-39.

Selvaraj, R. 1980. Cytotxonomical studies on some species of cycads. J. Indian Bot. Soc. 59: 320-324.

Schubert, I., Baumlein, H. and Wobus, U. 1978. In situ hybridization of iodinated 5S and 18/25S RNA to Vicia faba metaphase chromosomes. Biol. Zbl. 97: 129-135.

Tanaka, R. and Hizume, M. 1980. C-banding treatment for chromosomes of some gymnosperms. Bot. Mag. Tokyo 93: $167-170$.

Wolters, J. and Erdmann, V. A. 1988. Compilation of 5S rRNA and 5S rRNA gene sequences. Nucleic Acids. Res. 16: $r 1-r 70$. 